\title{
Aging and Pensions in General Equilibrium: Labor Market Imperfections Matter*
}

\author{
David de la Croix $^{a}$, Olivier Pierrard ${ }^{b}$, Henri R. Sneessens ${ }^{c \dagger}$ \\ ${ }^{a}$ CORE and IRES, Université catholique de Louvain \\ ${ }^{b}$ Banque centrale du Luxembourg and IRES, Université catholique de Louvain \\ ${ }^{c}$ CREA, Université du Luxembourg; IRES, Université catholique de Louvain, \\ and IZA, Bonn \\ May 2012
}

\begin{abstract}
We re-examine the effects of population aging and pension reforms in an OLG model with labor market frictions. The most important feature brought about by labor market frictions is the connection between the interest rate and the unemployment rate. Exogenous shocks (such as aging) leading to lower interest rates also imply lower equilibrium unemployment rates, because lower capital costs stimulate labor demand and induce firms to advertise more vacancies. These effects may be reinforced by increases in the participation rate of older workers, induced by the higher wage rates and the larger probability of finding a job. These results imply that neglecting labor market frictions and employment rate dynamics may seriously bias the evaluation of pension reforms when they have an impact on the equilibrium interest rate.

Keywords: Overlapping Generations, Search Unemployment, Labor Force Participation, aging, Pensions, Labor Market

JEL-Code: E24, H55, J26, J64
\end{abstract}

\footnotetext{
${ }^{*}$ David de la Croix and Henri Sneessens acknowledge the financial support of the Belgian French speaking community (ARC conventions 09-14/019 on "Geographical mobility of factors"). This paper was partly written while Henri Sneessens was visiting the Banque centrale du Luxembourg. The views expressed in this paper are personal views of the authors and do not necessarily reflect those of the Banque centrale du Luxembourg or the Eurosystem.

${ }^{\dagger}$ Corresponding author: Henri R. Sneessens (henri.sneessens@uni.lu) CREA, University of Luxembourg, 162a, avenue de la Faïencerie, L-1511 Luxembourg
} 


\section{Introduction}

Declining fertility, increasing longevity, and the aging of the baby-boom generation will all contribute to substantial increases of the old-age dependency ratio, especially in Western countries. Most of the increase in the old-age dependency ratio is expected to take place between now and 2050. This has raised concern about the sustainability of existing pay-as-you-go (PAYG) public pension schemes (see for instance Gruber and Wise, 2004, 2005) and has motivated pension reform plans.

It is now well understood that a correct appraisal of population aging and pension reform effects calls for a general equilibrium approach. OLG models such as those developed by Auerbach and Kotlikoff (1987) (deterministic setting) and Ríos-Rull (1996) (stochastic set-up) provide a useful analytical framework to obtain quantitative evaluations (see for instance Börsch-Supan et al., 2002, 2006, and the series of papers presented at the Carnegie-Rochester Conference, 2007). All these studies point out that population aging will make labor relatively scarcer and change equilibrium factor prices. Wages are expected to rise and interest rates to fall. Because aging is a worldwide but unsynchronized phenomenon, savings rates are expected to evolve differently in different countries, leading to significant international capital flows. Börsch-Supan et al. (2006) and Attanasio et al. (2007) both emphasized that a proper evaluation of the impact of aging on equilibrium prices and quantities calls for a multi-country approach. However, Attanasio et al. (2007) suggested that accounting for international capital flows might have little impact on

the fiscal variables themselves, because of the counteracting effects of interest and wage rate changes (for instance, lower capital tax revenues compensated for by higher labor tax revenues following an increase in payroll or consumption taxes).

Most existing models rely though on quite streamlined representations of the labor market and assume perfect competition. The focus is on individual hours of work rather than employment. In this context, considering endogenous rather than exogenous labor supply decisions barely changes the estimated quantitative impact of population aging (see for instance Attanasio et al., 2007, Krueger and Ludwig, 2007). As noted by Lucas (2007), neglecting labor adjustments along the extensive margin may be quite misleading. Such adjustments can play a significant role, especially in countries (like many European ones) where labor market imperfections and institutions can have a strong, age-specific impact on job creation and destruction.

The aim of this paper is to allow for such effects and evaluate their quantitative contribution to the macroeconomic effects of population aging. To that end, we combine two strands of research, life-cycle and search/matching models. Labor market imperfections are modelled as in Pissarides (2000), with matching and wage bargaining. To concentrate on the extensive margin effects, we shut off the intensive margin channels by assuming that each worker supplies inelastically one unit of labor. Changes in total hours of work are solely due to changes in the 
number of employed workers ${ }^{1}$. We furthermore allow for early-retirement effects.

It is well documented that participation rates vary over the life-cycle. Participation rates of middle-aged workers (25-55) are high and similar in both the US and the EU. The participation rates of older $(>55)$ workers are however lower in the EU. The literature stresses that differences in older participation rates reflect cross-country differences in labor market frictions and in the generosity of early-retirement provisions. Several empirical studies have shown that financial incentives do have a significant impact on early-retirement decisions (see for instance Gruber and Wise, 1999 or Duval, 2003, and the references therein). Although the official retirement age is exogenous in most countries, the actual average retirement age is endogenous and contributes to explaining the lower employment rate of older workers. Like Heijdra and Romp (2007), we thus distinguish the normal (compulsory) retirement age (65 years) and the early eligibility age (55). Workers may choose to retire between 55 and 65, and receive then an early-retirement compensation. Like Börsch-Supan et al. (2006), we consider a stylized two-tier pension system, so that after 65 the revenue of pensioners is made up of two components, a public PAYG pension and a private pre-funded pension (the revenue from accumulated savings).

A few studies have already examined some of the consequences of introducing life-cycle features into frictional labor markets; none of them has however evaluated the effects of future demographic trends. Hairault et al. (2010) examined early-retirement decisions and job search intensities in a search model à la McCall (1970), with exogenous wage distribution extended to include stochastic aging. The emphasis is on the relationship between the time to the retirement age and the financial incentives to invest in search activities. Chéron et al. (2008, 2011) developed this modelling strategy further. They introduced a matching process similar to that used by Mortensen and Pissarides (1994) adapted to include finite lifetimes. They showed that in some circumstances (in particular at fixed, age-independent worker productivity) the job destruction rate is higher for older workers, because the time horizon relevant for the employment decision decreases with age. In these models, there is no post-retirement consumption and no savings; the interest rate is exogenous.

Our model has three main building blocks (i) demographics; (ii) labor market frictions and institutions (including early-retirement provisions); (iii) life-cycle consumption and savings. Ríos-Rull (2001) emphasized the importance of a careful description of the demographic process, which can vary a lot from country to country. To fit actual data, we use French mortality, fertility and migration rates, so that the size of each cohort in every period coincides with the most recent demographic projections. We assume no aggregate uncertainty. In line with most of the literature, we also assume perfect risk sharing across individuals of a given generation,

\footnotetext{
${ }^{1}$ Börsch-Supan and Ludwig (2010) distinguish labor supply adjustments along both the extensive and the intensive margins and discuss the connections/interactions between pension reforms and labor market reforms. Changes along the extensive margin however remain exogenous to the model.
} 
so that individuals are perfectly insured against life and income uncertainty. ${ }^{2}$ There are no intended bequests. All workers are perfect substitutes, although the worker's productivity is age-dependent. There is no age discrimination, so that firms posting a vacancy may end up hiring a worker of any age category. We examine in this setup the effects of population aging and pension reforms on equilibrium unemployment and activity rates, and on the cost of public PAYG pensions as a percentage of GDP. In order to focus on labor market imperfections and their consequences, we do not at this stage build a multi-country model. We consider a single country, and illustrate the potential impact of international capital flows by comparing two polar cases, the closed and the small open economy case.

We use numerical simulations to examine the properties of our model and the consequences of aging and pension reforms. The most important feature brought about by labor market frictions is the connection between the interest rate and the unemployment rate. Exogenous shocks (like aging or pension reforms) leading to lower interest rates also imply lower equilibrium unemployment rates. This is because lower capital costs stimulate labor demand and induce firms to post more vacancies. The consequence is a higher employment rate and higher bargained wages. When participation of older workers is endogenous, these employment effects are reinforced by the increased participation rate of older workers, induced both by the higher wage rate and the larger probability of finding a job. It is shown in that context that neglecting labor market frictions and employment rate changes may lead to the underestimation of pension reform effects when they affect the equilibrium interest rate.

The remainder of this paper is organized as follows. The model is described in Section 2. The calibration is detailed in Section 3. Simulation results are presented and discussed in Section 4. in Section 5 we present our conclusions.

\section{The Model}

We develop a dynamic general equilibrium model with overlapping generations and frictions on the labor market. Frictions are modelled following Diamond, Mortensen, and Pissarides (DMP), with (exogenous) job destruction and a matching function. We assume perfect substitutability between all workers, although labor productivity is age-dependent. Perfect substitutability means that there is a single matching function (all vacancies can be filled by any worker, whatever his or her age). Age-directed search is not a credible strategy in our setup. Because the value of an unfilled vacancy is zero at equilibrium (free entry condition), a firm which wanted to target at, say, young workers, would eventually hire the first worker who applied,

\footnotetext{
${ }^{2}$ There are a few exceptions. Krueger and Ludwig (2007) and Hairault and Langot (2008), for instance, investigated the consequences of policy reforms (increased taxes or lower benefits) on inequality when financial markets are incomplete and individuals face idiosyncratic productivity shocks.
} 
provided the surplus to be shared was positive. Bargained wages will reflect differences in work efficiency.

\subsection{Demographics}

We do not model education and human capital accumulation and focus on the behavior of people between 25 and 104 (the maximum life duration). One period of time lasts five years. This periodicity seems a good compromise between the traditional two-period model which would be less suitable for calibration, and an annual model which would give no additional insight given our purpose to model demographic transitions and public finance dynamics rather than business cycles.

Each member of a given generation can live for up to sixteen five-year periods (from age 25 till 104), indexed from 0 to 15 . Let $Z_{a, t}$ denote the size of the generation reaching age $a$ at period t. The size of new generations changes over time at an exogenous rate $x_{t}$ :

$$
Z_{0, t}=\left(1+x_{t}\right) Z_{0, t-1}, \quad \forall t>0
$$

where $x_{t}$ includes both fertility and migration shocks at age zero. As in de la Croix et al. (2007), we assume that migrants of each generation have the same characteristics as natives. Abstracting from later migration shocks, the size of a given generation $t$ declines deterministically through time. This size is determined by a cumulative survival probability $\beta_{a, t+a}$ so that:

$$
Z_{a, t+a}=\beta_{a, t+a} Z_{0, t}+X_{a, t+a}, \quad \forall a \in\{1,2, \ldots 15\}
$$

where $0 \leq \beta_{a, t+a} \leq 1$ is decreasing in $a$, with $\beta_{0, t}=1$. Migration flows after age 25 are taken into account through $X_{a, t+a}$. Total (adult) population at time $t$ is equal to $Z_{t}=\sum_{a=0}^{15} Z_{a, t}$. The demographic growth and survival probability vector can vary over time. These changes are assumed to be exogenous.

We use the dummy variable $z_{a, t+a}$ to define the population of working age:

$$
P_{a, t+a}=z_{a, t+a} Z_{a, t+a}
$$

where $z_{a, t+a}=1$ for $0 \leq a \leq 7, z_{a, t+a}=0$ otherwise. We assume a mandatory retirement age of 65 , so that all people above $64(8 \leq a \leq 15)$ are inactive. We further assume that the participation rate between 25 and 54 is exogenous and normalized to unity. Between 55 and 64, workers can choose to take early-retirement. People of working age are thus either employed $(N)$, unemployed $(U)$, or on an early-retirement scheme $(E)$. Thus:

$$
\begin{aligned}
P_{a, t} & =N_{a, t}+U_{a, t}+E_{a, t}, \\
& =\left[n_{a, t}+u_{a, t}+e_{a, t}\right] P_{a, t}, \quad 0 \leq a \leq 7 \\
\Leftrightarrow \quad 1 & =n_{a, t}+u_{a, t}+e_{a, t},
\end{aligned}
$$


where lower-case $n, u$ and $e$ denote the proportion of individuals in each state. The earlyretirement rate before 55 is zero $\left(e_{a, t}=0\right.$ for $\left.a<6\right)$. Let $\lambda_{6, t}$ denote the fraction of people who choose to retire early and leave the labor market at age $a=6$ (between 55 and 60 ), so that the number of early retired workers of that age group is $E_{6, t}=\lambda_{6, t} P_{6, t}$. Similarly, let $\lambda_{7, t}$ denote the fraction of active workers who decide to leave the labor market at age $a=7$ (between 60 and 64). The total number of workers on early-retirement at time $t$ is then equal to:

$$
\begin{aligned}
E_{6, t}+E_{7, t}= & e_{6, t} P_{6, t}+e_{7, t} P_{7, t}, \\
\text { with } \quad & e_{6, t}=\lambda_{6, t}, \\
& e_{7, t}=\lambda_{6, t-1}+\lambda_{7, t}\left(1-\lambda_{6, t-1}\right) .
\end{aligned}
$$

\subsection{Labor Market Flows}

We assume a constant returns to scale matching function:

$$
M_{t}=M\left(V_{t}, \Omega_{t}\right)
$$

where $V_{t}$ and $\Omega_{t}$ stand respectively for the total number of vacancies and job seekers at the beginning of period $t . \Omega_{t}$ is the sum across all age categories:

$$
\begin{aligned}
\Omega_{t}=\sum_{a=0}^{7} \Omega_{a, t} \\
=P_{0, t}+\sum_{a=1}^{5}\left[1-(1-\chi) n_{a-1, t-1}\right] P_{a, t} \\
+\left[1-(1-\chi) n_{5, t-1}\right]\left(1-\lambda_{6, t}\right) P_{6, t} \\
+\left[\left(1-\lambda_{6, t-1}\right)-(1-\chi) n_{6, t-1}\right]\left(1-\lambda_{7, t}\right) P_{7, t} .
\end{aligned}
$$

At the beginning of period $t$, all new entrants $P_{0, t}$ are job seekers. Except for early-retirement decisions, job separations are determined by an exogenous job destruction rate $\chi$. Parameters $\lambda_{6, t}$ and $\lambda_{7, t}$ introduce the effects of early-retirement.

The probabilities of finding a job and of filling a vacancy are defined as follows:

$$
p_{t}=\frac{M_{t}}{\Omega_{t}} \quad \text { and } \quad q_{t}=\frac{M_{t}}{V_{t}} .
$$

The number of employed workers in age group $a$ is determined by the sum of non-destroyed jobs (when $a>0$ ) and new hires:

$$
\begin{aligned}
n_{a, t} & =p_{t} \frac{\Omega_{a, t}}{P_{a, t}} & & \text { for } a=0 ; \\
& =(1-\chi) n_{a-1, t-1}+p_{t} \frac{\Omega_{a, t}}{P_{a, t}} & & \text { for } 1 \leq a \leq 5 ; \\
& =\left(1-\lambda_{a, t}\right)(1-\chi) n_{a-1, t-1}+p_{t} \frac{\Omega_{a, t}}{P_{a, t}} & & \text { for } 6 \leq a \leq 7 .
\end{aligned}
$$


After substituting for $\Omega_{a, t}$, this equation becomes:

$$
\begin{aligned}
n_{a, t} & =p_{t}, & & \text { for } a=0 ; \\
& =\left(1-p_{t}\right)(1-\chi) n_{a-1, t-1}+p_{t} & & \text { for } 1 \leq a \leq 5 ; \\
& =\left(1-p_{t}\right)\left(1-\lambda_{a, t}\right)(1-\chi) n_{a-1, t-1}+p_{t}\left(1-\lambda_{a, t}\right) & & \text { for } a=6 ; \\
& =\left(1-p_{t}\right)\left(1-\lambda_{a, t}\right)(1-\chi) n_{a-1, t-1}+p_{t}\left(1-\lambda_{a, t}\right)\left(1-\lambda_{a-1, t-1}\right) & & \text { for } a=7 .
\end{aligned}
$$

The same equation can be written in terms of the probability of filling a vacancy $q_{t}$ by using $p_{t}=q_{t} V_{t} / \Omega_{t}$. Total employment will then be equal to:

$$
N_{t}=\sum_{a=0}^{7} N_{a, t}, \quad \text { with } N_{a, t}=n_{a, t} P_{a, t} .
$$

\subsection{Households}

It is assumed that each individual belongs to a representative household, one for each age category. There is no aggregate uncertainty, and all households have perfect foresight. There is perfect insurance against the adverse effects of individual lifetime uncertainty. There are no intended bequests. Participation rates of workers below 55 are assumed to be exogenous and normalized to unity. The household's decision variables are consumption, savings and early-retirement rates, subject to the lifetime budget constraint.

\section{Participation Decisions and early-retirement}

Participation decisions have been investigated separately in the OLG and the search/matching literature. Various contributions in the OLG literature have focused on the determinants of the optimal retirement age. Hu (1979) assumed that agents live for two periods. The optimal retirement age is determined by the optimal fraction of time devoted to leisure in the second period of life. He examined the effects of social security on capital accumulation and labor supply in a PAYG case. The short-run effects of pensions depended on the elasticities of demand and supply of labor; long-run effects were influenced by the elasticities of savings and bequests. Michel and Pestieau (1999) modeled the labor participation choice in a similar fashion. The fraction of time spent working in the second period declined when the size of the social security payment increase. For the first-best optimum (golden rule steady state) to be decentralized as a competitive equilibrium, both PAYG social security tax and the retirement age must be set optimally. De la Croix, Mahieu, and Rillaers (2004) also used a two-period lifetime setup to analyze retirement decisions. They focused on optimal dynamic adjustments following a fertility drop and showed that the optimal adjustment of the retirement age (the fraction of the second

period devoted to leisure) depends on preference and technology parameters. Boucekkine et al. 
(2002) and Heijdra and Romp (2009) have endogenous retirement in a continuous time OLG model with finite lifetimes and indivisible labor (participation is either 1 or 0 ). Heijdra and Romp (2009) focused on the effects of demographic shocks and pension benefits on individual early-retirement decisions. Their results suggest that only drastic reforms have a significant impact on individual retirement decisions.

None of the previous papers takes into account labor market frictions. Most contributions dealing with participation decisions in the search and friction literature have used models without savings and capital accumulation. Recently though, Ravn (2008) has used a stochastic growth model with infinitely lived consumers to investigate the role of endogenous participation decision on the transmission of shocks at business cycle frequencies. Labor is indivisible; individual workers are perfectly insured against idiosyncratic consumption risk, as in the lottery model developed by Rogerson (1988). This leads to a utility function linear in the participation rate, which implies a strong relationship between consumption and labor market tightness, the so-called consumption-tightness puzzle. Because of the linearity of the utility function, participation rates react too strongly to labor market tightness, which makes unemployment procyclical. To avoid this unrealistic implication, Den Haan and Kaltenbrunner (2009) assumed perfect risk sharing of both consumption and leisure. All consumers are part of a representative household and share their revenues. The household decides the per capita consumption level and the participation rate. This in effect amounts to assuming that labor is divisible, with each individual choosing the fraction of time spent on the labor market (as employed or unemployed). See Tripier (2003) for a similar approach.

Our model combines life-cycle features and labor market frictions. In order the avoid the consumption-tightness puzzle, we shall rely on the Den Haan and Kaltenbrunner (2009) specification and introduce it into our OLG structure. Without frictions, our specification would be similar to that used by Börsch-Supan et al. (2006) (i.e. in a perfect competition setup, with elderly workers characterized by stronger leisure preferences and choosing a smaller working time).

\section{Optimization Program of the Representative Household}

We can write the objective function of the household (effectively one cohort) as:

$W_{t}^{H}=\max _{c_{a, t+a}, \lambda_{6, t+6}, \lambda_{7, t+7}} \sum_{a=0}^{15}\left(\frac{1}{1+\theta}\right)^{a} \beta_{a, t+a}\left\{\mathcal{U}\left(c_{a, t+a}\right)-d^{n} n_{a, t+a} z_{a, t+a}+d_{a}^{e} \frac{\left(e_{a, t+a}\right)^{1-\phi}}{1-\phi} z_{a, t+a}\right\} Z_{0, t}$, 
where $\theta>0$ is the rate of time preference or the subjective discount rate $^{3}, \beta_{a, t+a}$ is a cumulative survival probability, $z_{a, t+a}$ is the working age dummy variable $\left(z_{a, t+a}=1\right.$ for $0 \leq a \leq 7,0$ otherwise), and $Z_{0, t}$ is the initial size of the cohort. Instantaneous utility is assumed to be separable. The utility of per capita consumption $c$ is represented by a concave function $\mathcal{U}$ (we shall use a logarithmic function). The marginal disutility of working is assumed to be constant ${ }^{4}$ and equal to $d^{n}$. The extra utility derived from early-retirement is represented by a concave function of the early-retirement rate $e(0<\phi<1)$. The decision variables are $c, \lambda_{6}$ and $\lambda_{7}$. These last two variables refer to the fraction of agents in the corresponding age groups who decide to take early-retirement and leave the labor market, at ages 55 and 60 respectively. Employment rates $n_{a, t+a}$ and early-retirement rates $e_{a, t+a}$ (and their the connection to the $\lambda$ 's) are given by Equations (5) and (9).

The household's flow budget constraint at time $t+a$ takes the form:

$$
\begin{aligned}
{\left[\left(1-\tau_{t+a}^{w}\right) w_{a, t+a} \cdot n_{a, t+a}\right.} & \left.+b_{a, t+a}^{u} \cdot u_{a, t+a}+b_{a, t+a}^{e} \cdot e_{a, t+a}\right] \cdot z_{a, t+a}+b_{a, t+a}^{i} \cdot\left(1-z_{a, t+a}\right) \\
& +\frac{\beta_{a-1, t+a-1}}{\beta_{a, t+a}} R_{t+a} s_{a-1, t+a-1}=\left(1+\tau_{t+a}^{c}\right) c_{a, t+a}+s_{a, t+a}
\end{aligned}
$$

Wage and consumption tax rates are given by $\tau^{w}$ and $\tau^{c}$ respectively; $b_{a, t+a}^{u}, b_{a, t+a}^{e}, b_{a, t+a}^{i}$ are the replacement benefits received respectively by the unemployed worker, the early retiree and the pensioner; $s_{a, t+a}$ is the financial wealth accumulated at time $t+a$, in per capita terms. This financial wealth is held in the form of either shares or physical capital. Because there is perfect insurance against individual lifetime uncertainty (as if there were a perfect annuity market), the total return to savings is equal to the gross risk-free interest rate $R_{t+a}$ divided by the survival probability $\beta_{a, t} / \beta_{a-1, t-1}$.

The optimal consumption plan must satisfy the usual Euler equation:

$$
\frac{u_{c_{a, t+a}}^{\prime}}{1+\tau_{t+a}^{c}}=\frac{R_{t+a+1}}{1+\theta} \frac{u_{c_{a+1, t+a+1}}^{\prime}}{1+\tau_{t+a+1}^{c}} .
$$

After substitution and rearrangements, the condition determining the optimal proportion of early retirees aged 60 can be shown to be:

$$
\begin{aligned}
\frac{b_{7, t+7}^{e}}{\left(1+\tau_{t+7}^{c}\right) c_{7, t+7}}+d_{7}^{e}\left(e_{7, t+7}\right)^{-\phi}=\pi_{7, t+7} & {\left[\frac{\left(1-\tau_{t+7}^{w}\right) w_{7, t+7}}{\left(1+\tau_{t+7}^{c}\right) c_{7, t+7}}-d^{n}\right] } \\
+ & \left(1-\pi_{7, t+7}\right)\left[\frac{b_{7, t+7}^{u}}{\left(1+\tau_{t+7}^{c}\right) c_{7, t+7}}\right],
\end{aligned}
$$

where $\pi$ is the unconditional probability of being employed (i.e., the probability that an active worker chosen at random is actually employed). A similar condition holds for early-retirement

\footnotetext{
${ }^{3}$ As stressed by Ríos-Rull(2001), $\theta$ can represent both pure time preference and the effect of family size changes (implying that consumption is enjoyed differently at different ages).

${ }^{4}$ Our formulation normalizes the disutility of search activities of the unemployed to zero. Setting $d^{n} \geq 0$ amounts to assuming that the disutility of working can be larger than that of searching.
} 
at age 55 (see details in the appendix A). Equation (12) says that the household's optimal earlyretirement rate is such that the marginal utility of early-retirement (early-retirement income plus leisure utility) is equal to the expected marginal utility of remaining active on the job market (wage income net of labor disutility and unemployment benefit, each weighted by their respective probability). Which member of the household will actually take early-retirement does not depend on the initial employment status. Both employed and unemployed workers may become early retirees. This follows from our specification of labor market flows (Equation (9)). Assuming that only previously unemployed workers can shift to early-retirement would be much too restrictive and unrealistic. Firms do take advantage of the generosity of earlyretirement schemes to adjust the number of their employees, while elderly workers do agree to quit jobs earlier if the early-retirement compensation is appropriate.

For later use, we also note that the value of an additional job for a household of age $a$ is given by:

$$
\begin{aligned}
\frac{1}{u_{c_{a, t}}^{\prime}} \frac{\partial W_{t}^{H}}{\partial N_{a, t}} & =\frac{1}{u_{c_{a, t}}^{\prime}} \frac{1}{z_{a, t} Z_{a, t}} \frac{\partial W_{t}^{H}}{\partial n_{a, t}} \\
& =\sum_{j=0}^{7-a} \frac{\beta_{a+j, t+j}}{\beta_{a, t}}\left(\frac{1}{1+\theta}\right)^{j} \frac{u_{c_{a+j, t+j}}^{\prime}}{u_{c_{a, t}}^{\prime}}\left\{\frac{\left(1-\tau_{t+j}^{w}\right) w_{a+j, t+j}-b_{a+j, t+j}^{u}}{\left(1+\tau_{t+j}^{c}\right)}-\frac{d^{n}}{u_{c_{a+j, t+j}}^{\prime}}\right\} \frac{\partial n_{a+j, t+j}}{\partial n_{a, t}}
\end{aligned}
$$

where $\partial n_{a+j, t+j} / \partial n_{a, t}$ can be obtained from Equation (9).

\subsection{Firms}

There are two productive factors, labor and capital. Labor is measured in efficiency units. Efficiency may vary across age (because of experience) and across generations (because of education). We define the total labor input as follows:

$$
H_{t}=\sum_{a=0}^{7} h_{a, t} \cdot N_{a, t} .
$$

We assume a constant-return-to-scale production function in labor and capital:

$$
Y_{t}=A_{t} F\left(K_{t}, H_{t}\right)
$$

where $A_{t}$ stands for total factor productivity. Firms rent capital at cost $v_{t}=R_{t}+\delta-1$ and pay a gross wage $w_{a, t}$ to workers of age $a$. We denote by $\zeta$ the employer wage tax. The representative 
firm maximizes the discounted value of all the dividends (profits) that will be distributed to its shareholders. Profits at time $t$ are given by:

$$
\Pi_{t}=F\left(K_{t}, H_{t}\right)-v_{t} K_{t}-\sum_{a=0}^{7}\left(1+\zeta_{t}\right) w_{a, t} N_{a, t}-\mathrm{a} V_{t}
$$

where "a" stands for the cost of posting a vacancy. The value of the firm can thus be written as: ${ }^{5}$

$$
W_{t}^{F}=\max _{K_{t}, V_{t}}\left\{F\left(K_{t}, H_{t}\right)-v_{t} K_{t}-\sum_{a=0}^{7}\left(1+\zeta_{t}\right) w_{a, t} N_{a, t}-\mathrm{a} V_{t}\right\}+R_{t+1}^{-1} W_{t+1}^{F}
$$

subject to Equation (9) and $p_{t}=q_{t} V_{t} / \Omega_{t}$. The first-order optimality conditions are

$$
\begin{aligned}
v_{t} & =F_{K_{t}}, \\
\mathrm{a} & =q_{t} \sum_{a=0}^{7} \frac{\Omega_{a, t}}{\Omega_{t}} \frac{\partial W_{t}^{F}}{\partial N_{a, t}},
\end{aligned}
$$

where $\frac{\partial W_{t}^{F}}{\partial N_{a, t}}$ is the value at time $t$ of an additional worker of age $a$. With a job destruction rate $\chi$, this value is equal to:

$$
\begin{aligned}
\frac{\partial W_{t}^{F}}{\partial N_{a, t}}= & \frac{1}{z_{a, t} Z_{a, t}} \frac{\partial W_{t}^{F}}{\partial n_{a, t}} \\
=\sum_{j=0}^{7-a} \frac{\beta_{a+j, t+j}}{\beta_{a, t}} R_{t, t+j}^{-1}\left(1-\lambda_{a+j-1, t+j-1}\right)\left(1-\lambda_{a+j, t+j}\right)(1-\chi)^{j} & \cdot\left\{h_{a+j, t+j} F_{H_{t+j}}-\left(1+\zeta_{t+j}\right) w_{a+j, t+j}\right\},
\end{aligned}
$$

where $\lambda_{a+i, t+i} \equiv 0$ for $a+i<6$.

\subsection{Government}

We assume that unemployment and (early or standard) retirement benefits are determined by an exogenous fraction of the relevant gross wage, so that

$$
\begin{array}{ll}
b_{a, t}^{u}=\rho_{t}^{u} w_{a, t} & \text { for } \quad 0 \leq a \leq 7 \\
b_{a, t}^{e}=\rho_{t}^{e} w_{a, t} & \text { for } \quad 6 \leq a \leq 7 \\
b_{a, t}^{i}=\rho_{t}^{i} \sum_{i=0}^{3} \frac{w_{a-i, t-i}}{4} & \text { for } \quad 8 \leq a \leq 15 .
\end{array}
$$

\footnotetext{
${ }^{5}$ Shareholders may belong to different age groups and have different consumption levels. Still, they all have the same discount factor given by $\frac{1}{1+\theta} \frac{u_{c a+1, t+1}^{\prime}}{u_{c_{a, t}}^{\prime}}=R_{t+1}^{-1}, \forall a \epsilon\{0,14\}$.
} 
The retirement benefit is computed from the average wage during the last four periods. Total transfer expenditures are then equal to:

$$
T_{t}=\rho_{t}^{u} \sum_{a=0}^{7} w_{a, t} u_{a, t} Z_{a, t}+\rho_{t}^{e} \sum_{a=6}^{7} w_{a, t} e_{a, t} Z_{a, t}+\rho_{t}^{i} \sum_{i=0}^{3} \frac{w_{a-i, t-i}}{4} \sum_{a=8}^{15} Z_{a, t} .
$$

Public consumption is assumed to be a fraction of output, net of vacancy costs, i.e.

$$
G_{t}=\bar{g}\left(Y_{t}-\mathrm{a} V_{t}\right)
$$

We further assume that the "government" balances its budget in every (five-year) period by adjusting consumption taxes (i.e., $\tau_{t}^{c}$ is the adjusting variable): ${ }^{6}$

$$
\tau_{t}^{c} C_{t}+\left(\tau_{t}^{w}+\zeta_{t}\right)\left(\sum_{a} w_{a, t} n_{a, t} P_{a, t}\right)=G_{t}+T_{t}
$$

where aggregate consumption $C_{t}=\sum_{a} c_{a, t} Z_{a, t}$. For convenience, we assume no public debt. Public debt could be introduced by postulating an exogenous path of the debt, and assuming that the deficit adjusts (via $\tau^{c}$ ) to match that path.

\section{$2.6 \quad$ Wages}

Wages are renegotiated in every period. They are determined by a standard Nash bargaining rule:

$$
\max _{w_{a, t}}\left(\frac{\partial W_{t}^{F}}{\partial N_{a, t}}\right)^{1-\eta}\left(\frac{1}{u_{c_{a, t}^{\prime}}^{\prime}} \frac{\partial W_{t}^{H}}{\partial N_{a, t}}\right)^{\eta}
$$

where $\partial W_{t}^{H} / \partial N_{a, t}$ is given by Equation (13) and $\partial W_{t}^{F} / \partial N_{a, t}$ by Equation (19).

The first-order optimality condition can then be written:

$$
(1-\eta) \frac{1}{u_{c_{a, t}}^{\prime}} \frac{\partial W_{t}^{H}}{\partial N_{a, t}}=\eta \frac{1-\tau_{t}^{w}}{\left(1+\zeta_{t}\right)\left(1+\tau_{t}^{c}\right)} \frac{\partial W_{t}^{F}}{\partial N_{a, t}} .
$$

\subsection{Capital Market Equilibrium}

Let $Q_{t}$ denote the total financial value of firms at time $t$. In our deterministic setup, the return on equities must be equal to the market interest rate. In other words, the value of equities must be such that, for all $t \geq 0$ :

$$
\frac{Q_{t+1}+\Pi_{t+1}}{Q_{t}}=R_{t+1} .
$$

The left-hand side is the return of one unit of savings investment in equities while the right-hand side is the return if invested in firms' bonds.

\footnotetext{
${ }^{6}$ Changes in $\tau_{t}^{c}$ affect all incomes in the same way, while changes in $\tau_{t}^{w}$, for instance, would change net replacement rates.
} 
Equilibrium on the capital market then implies that:

$$
K_{t+1}+Q_{t}=\sum_{a=0}^{14} s_{a, t} Z_{a, t}
$$

\subsection{Intertemporal General Equilibrium}

We shall consider two versions of the model, one with frictions and the other with perfect competition on the labor market. The two corresponding intertemporal general equilibria are formally defined In Definitions 1 and 2 below.

Definition 1 Given the following exogenous processes and initial conditions:

- demographic variables $\left\{x_{t}\right\}_{t=0 . .+\infty}$ (fertility), $\left\{\beta_{a, t}\right\}_{t=0 . .+\infty}^{a=0.15}$ (mortality), $\left\{X_{a, t}\right\}_{t=0 . .+\infty}^{a=0.15}$ (migration),

- policy variables $\left\{\rho_{t}^{u}, \rho_{t}^{e}, \rho_{t}^{i}\right\}_{t=0 . .+\infty}$ (replacement rates) and $\left\{\tau_{t}^{w}, \zeta_{t}\right\}_{t=0 . .+\infty}$ (tax rates),

- initial population $\left\{Z_{a,-1}\right\}^{a=0.15}$, assets $\left\{s_{a,-1}\right\}^{a=0.14}$ and capital stock $\bar{K}_{0}<\sum_{a=0}^{14} s_{a,-1} Z_{a,-1}$,

an inter-temporal equilibrium with perfect foresight and labor market frictions is such that:

1. saving $\left\{s_{a, t}\right\}_{t=0 . .+\infty}^{a=0.14}$, consumption $\left\{c_{a, t}\right\}_{t=0 . .+\infty}^{a=0.15}$ and early-retirement decisions $\left\{e_{a, t}, \lambda_{a, t}\right\}_{t=0 . .+\infty}^{a=6,7}$ maximize households' utility (10) subject to budget constraint (11) and to (5);

2. capital input $\left\{K_{t}\right\}_{t=0 .++\infty}$, posted vacancies $\left\{V_{t}\right\}_{t=0 . .+\infty}$ and output $\left\{Y_{t}\right\}_{t=0 . .+\infty}$ maximize firms' profits (16) subject to (8), (9), (14), and $K_{0}=\bar{K}_{0}$;

3. the number of new hires $\left\{M_{t}\right\}_{t=0 . .+\infty}$, the probability of finding a job $\left\{p_{t}\right\}_{t=0 . .+\infty}$ and of filling a vacancy $\left\{q_{t}\right\}_{t=0 . .+\infty}$, and the employment rates $\left\{n_{a, t}\right\}_{t=0 . .+\infty}^{a=0.7}$ satisfy the matching technology (6), (8) and (9);

4. total population and the population of working age $\left\{Z_{a, t}, P_{a, t}\right\}_{t=0 . .+\infty}^{a=0.7}$, and the number of job seekers $\left\{\Omega_{t}\right\}_{t=0 .+\infty}$ satisfy the population dynamics (1), (2), (3) and (7);

5. unemployment $\left\{u_{a, t}\right\}_{t=0 .++\infty}^{a=0.7}$ is such that the time constraint (4) holds;

6. wages $\left\{w_{a, t}\right\}_{t=0 . .+\infty}^{a=0.7}$ are negotiated following the Nash bargaining rule (24);

7. government benefits $\left\{b_{t}^{u} b_{t}^{e}, b_{t}^{i}\right\}_{t=0 . .+\infty}$ follow the rules defined by (20), and government spending $\left\{G_{t}\right\}_{t=0 . .+\infty}$ follow (22); 
8. consumption taxes $\left\{\tau_{t}^{c}\right\}_{t=0 .++\infty}$ are set by the government to balance its budget (23);

9. stock market prices and interest rate $\left\{Q_{t}, R_{t}\right\}_{t=0 . .+\infty}$ satisfy the arbitrage condition (26) and the financial market clearing condition (27).

Definition 2 Given the same exogenous processes and initial conditions as in Definition 1, an inter-temporal equilibrium with perfect foresight with frictionless labor market is such that:

1. saving $\left\{s_{a, t}\right\}_{t=0 . .+\infty}^{a=0.14}$, consumption $\left\{c_{a, t}\right\}_{t=0 . .+\infty}^{a=0.15}$ and early-retirement decisions $\left\{e_{a, t}, \lambda_{a, t}\right\}_{t=0 . .+\infty}^{a=6,7}$ maximize households' utility (10) subject to budget constraint (11) and to (5);

2. capital input $\left\{K_{t}\right\}_{t=0 . .+\infty}$, posted vacancies $\left\{V_{t}\right\}_{t=0 . .+\infty}$ and output $\left\{Y_{t}\right\}_{t=0 . .+\infty}$ maximize firms' profits (16) subject to $q_{t}=1$, (9), (14), $a=0$ and $K_{0}=\bar{K}_{0}$;

3. the number of new hires $\left\{M_{t}\right\}_{t=0 .++\infty}$ satisfies $M_{t}=V_{t}$, the probability of finding a job $\left\{p_{t}\right\}_{t=0 . .+\infty}$ and of filling a vacancy $\left\{q_{t}\right\}_{t=0 . .+\infty}$ satisfy $q_{t}=p_{1}=1$, and the employment rates $\left\{n_{a, t}\right\}_{t=0 . .+\infty, a=0 . .7}$ satisfy $(9)$;

4. total population and the population of working age $\left\{Z_{a, t}, P_{a, t}\right\}_{t=0 . .+\infty}^{a=0.7}$, and the number of job seekers $\left\{\Omega_{t}\right\}_{t=0 . .+\infty}$ satisfy the population dynamics (1), (2), (3) and (7);

5. wages $\left\{w_{a, t}\right\}_{t=0 . .+\infty}^{a=0.7}$ are such that $n_{a, t}+e_{a, t}=1$;

6. government benefits $\left\{b_{t}^{u} b_{t}^{e}, b_{t}^{i}\right\}_{t=0 . .+\infty}$ follow the rules defined by (20);

7. consumption taxes $\left\{\tau_{t}^{c}\right\}_{t=0 . .+\infty}$ are set by the government to balance its budget (23);

8. the interest rate $\left\{R_{t}\right\}_{t=0 .++\infty}$ satisfies the financial market clearing condition (27).

\section{Calibration}

Our objective is to reexamine the channels by which population aging affects the economy in an OLG setup with labor market frictions. More specifically we want to evaluate the role of labor market imperfections and the interactions between pension reforms and the labor market. Our calibration is meant to represent a European situation, such as France, with fairly generous unemployment benefits and public pensions, and substantial early-retirement benefits inducing low participation rates among elderly workers. The parameters of the model fall into four categories: (i) general technological and preference parameters; (ii) parameters specific to the frictional labor market; (iii) parameters determining taxes and transfers; (iv) parameters determining demographic changes (fertility, mortality, migration). 


\section{Technological and Preference Parameters}

We assume a constant-returns-to-scale Cobb-Douglas production function. The elasticity of output with respect to capital is set at $\alpha=0.33$. In order to focus on the effects of demographic changes, we leave aside technological progress and assume constant values of the TFP and age-specific human capital parameters $\left(A_{t}\right.$ and $h_{a, t}$ respectively). To reproduce the life cycle profile of wages, we assume that a worker's productivity increases with age until 50, and then decreases, but only very slowly so, as suggested by empirical findings (see for instance Kotlikoff and Gokhale, 1992, Johnson and Neumark, 1996 or Aubert and Crépon, 2003). Bargained wages broadly follow the same pattern, with a negative age effect (due the shorter expected job duration of older workers) on top of the productivity effect.

We assume that the instantaneous utility is logarithmic in consumption, so that the wealth and substitution effects of a change in the interest rate cancel each other out. The subjective rate of time preference is given the customary value of $1 \%$ per quarter. The depreciation rate of capital is then set at $2.5 \%$ per quarter, so as to obtain a capital-output ratio equal to 2.40 on a yearly basis in 2010 ( 2.5 in the final steady state). There is no bequest motive. Given the assumed demographic structure (see below), the resulting real interest rate is $6.80 \%$ p.a. in 2010 (5.3\% in the final steady state), in line with the equilibrium interest rates in similar models (e.g. 6.6\% in 2005 in Attanasio et al., 2007, and 7.4\% in Krueger and Ludwig, 2007). Although these interest rate levels may seem high at first sight, Attanasio et al. (2007, p.165) notice that they are still lower than the postwar real return on equities. Individual consumption rises over the life cycle and savings are negative during the first two periods of life.

We set the labor disutility parameter $d^{n}$ at 0.25 . It implies that, for the different generations, the marginal disutility of employment (divided by the marginal utility of consumption) represents between $15 \%$ and $20 \%$ of the wage income in 2010 (similar numbers in the final steady state). This relative value of domestic activity is hard to measure empirically. Using German data, Frick at al. (2011) show that the average wage income advantages from home production is between $30 \%$ and 60\%, depending on the methodology. However, using a GDP approach, Giannelli et al. (2012) find that Germany has by far the highest value of home production among the $24 \mathrm{EU}$ countries. Our values therefore seem acceptable in light of these results. In the EU15, early-retirement rates for workers aged 50-59 and 60-64 were respectively 16\% and $52 \%$ in $2010 .^{7}$ The values of the two leisure (early-retirement) parameters $d_{6}^{e}=0.031$ and $d_{7}^{e}=0.049$ are chosen to reproduce these two early-retirement numbers in the year 2010 (note

\footnotetext{
${ }^{7}$ Because our analysis abstracts from people who are neither active nor early retired, senior activity rates are computed from the data (OECD.Stat) by subtracting from the population the fraction of people aged 55-64 who are neither contributors nor pensioners. This fraction is approximated by the proportion of non-active population aged 50-54 years over the corresponding previous periods of time. To limit this adjustment, we also only focus on the male population.
} 
that we respectively obtain $3 \%$ and $8 \%$ in the final steady state). Parameter $\phi$ is set to 0.80 , which implies a Frisch elasticity of around 0.6, in line with estimated values (see Den Haan and Kaltenbrunner, 2009) ${ }^{8}$.

\section{Labor Market Parameters}

The matching process is represented by a constant-returns-to-scale Cobb-Douglas function. The elasticity of matches with respect to vacancies $\nu$ and the bargaining power of workers $\eta$ are both fixed at 0.50, as it is generally the case in the related literature. For the EU15, Bassanini and Marianna (2009, Figure 4) report an average job destruction rate of about $8 \%$ per annum in some European countries (Germany, Finland and Sweden). We therefore fix our quarterly job separation rate $\chi$ at $2 \%$ (this gives a destruction rate of $33.24 \%$ over a five-year period). The matching efficiency parameter $\mu$ and the vacancy cost a are chosen to be 0.90 and 43.5 respectively, so that the final steady state probabilities (over a five-year period) of finding a job $p$ and of filling a vacancy $q$ are both equal to $90 \%$ in the final steady state. Imposing $p=q$ at the steady state, which implies a unitary labor market tightness, is a standard strategy in the related literature (see for instance de Walque et al., 2009).

This calibration also allows to capture quite well several labor market statistics for the year 2010. First, Figure 1 shows that our simulated employment rates per age are very close to the corresponding employment rates in the EU15. ${ }^{9}$ Second, $q=0.98$ in 2010 . It means the probability that a vacancy is unfilled after 5 years is $2 \%$. Farm (2004) reports that between 2000 and 2004, around 40\% of Swedish vacancies were not yet filled after one quarter. The Finish Job vacancy survey (www.stat.fi) provides a similar number for the years 2006-2011. The French Employment Agency reports that in 2007, 10.5\% of vacancies were unfilled after one year (see Fondeur and Zanda, 2009, for a discussion). Although the notion of unfilled vacancies differs across studies and countries, we can reasonably think that most vacancies are filled after a five-year period which justifies our $q=0.98$. Moreover, we have $p=0.82$ which, together with $q=0.98$, gives a labor market tightness of 0.84 . Third, the per period value of the vacancy cost a represents $36 \%$ of the gross wage of a 45 -year-old worker and, although there is little empirical evidence on the magnitude of these costs, seems in a plausible range.

\section{[TABLE 1 ABOUT HERE] [FIGURE 1 ABOUT HERE]}

\footnotetext{
${ }^{8}$ The Frisch elasticity is $\frac{e}{1-e} \frac{1}{\phi}$.

${ }^{9}$ EU15 data are from OECD.Stat. As already explained in footnote 7 , we remove from these data people who are neither active nor early retired, to be in accordance with our model. Again, we only focus on the male population.
} 


\section{Taxes and Transfers}

Government consumption is a constant fraction of GDP $(\bar{g}=20 \%)$. The gross replacement rate for unemployed workers is fixed at $\rho^{u}=0.40$, implying a net replacement rate of about $47 \%$. Actual net replacement rates vary a lot across countries and unemployment durations. The chosen value is close to the OECD median value for a two-year unemployment spell (see OECD, 2009, Table 1.6). The replacement rate for early-retirement is assumed to remain constant, at $\rho^{e}=0.50$. The reference wage used to compute pension benefits is typically an average of wages in the best years of activity. For simplicity, we define the reference wage as the average wage of workers aged 45-64. At a given replacement rate, our formulation implies that pensions are indexed on current wages (rather than prices). We calibrate the pension replacement rate $\rho_{t}^{i}$ on French data, as reported in EC (2009). The 2000 value is $\rho^{i}=0.55$. The French pension reforms of 1993 and 2003 are however expected to progressively decrease this replacement rate through three main channels: (i) reference wage calculated over a longer period; (ii) indexation to prices rather than wages; (iii) increase in the number of years of activity required to have full pension rights ${ }^{10}$. The effects of these reforms will appear progressively in future years and should mean a 20 percentage points decrease in the value of the replacement rate by 2035 (30 percentage points by the year 2050). These changes are included in our base scenario (see Table $1)$.

\section{Demographic Variables}

Expected population growth rates vary across countries. We chose to calibrate the main demographic variables on French data. Survival probabilities from 1900 till 2100 are taken from Vallin and Meslé (2001). The expected decrease in mortality rates is illustrated in the left panel of figure 2. These changes imply that life expectancies at birth would increase from 77.9 years in 2000 to 86.5 in 2050 and 90.8 in 2095. Fertility and migration shocks (variables $x_{t}$ and $X_{a, t+a}$ ) are calibrated so as to reproduce the population changes (by age category) observed or expected to take place from 1900 till 2100. The projections till 2050 are the latest ones published by INSEE (see Robert-Bobée, 2006, updated in April 2007) ${ }^{11}$. We assume that the population stabilizes progressively after 2050. These projections are illustrated in the right panel of Figure 2. The reported population changes (total and adults over 24) imply a quasi-constant population of age 25-64. The dependency ratio (defined as the ratio between the population over 64 and that aged 25-64) increased around 10 percentage points between 1950 and 2000; it is expected to double during the next sixty years, reaching $60 \%$ in 2060 and stabilizing at $69 \%$ after 2100 . [FIGURE 2, PANELS a AND b ABOUT HERE]

\footnotetext{
${ }^{10}$ See Bozio (2008) for an ex post evaluation of the effects of this reform.

${ }^{11}$ Available at http://www.insee.fr/fr/themes/document.asp?ref_id=PROJPOPACT0650\#a1
} 


\section{Eigenvalues}

Once the model has been calibrated, we can assess the convergence speed by computing the eigenvalues of the Jacobian matrix of the linearized system around the steady state. It is generally found that such eigenvalues are complex numbers which generate non-monotonic dynamics (see Azariadis, Bullard and Ohanian, 2004). Figure 3 represents the stable eigenvalues of the two models. Considering only the largest eigenvalues, which are those that matter as far as sluggishness is concerned, we observe that those of the model with frictions are larger, but the difference is very small. We conclude from this that labor market frictions do not mean more sluggishness compared to a Walrasian set-up, at least in an OLG model with five-year periods.

[FIGURE 3 ABOUT HERE]

\section{Simulation Results}

We first present the simulation results obtained in the base scenario and illustrate the specific impact of migration and fertility shocks. We then highlight the role of labor market imperfections by contrasting the results of the base scenario with those obtained under the assumption of a competitive labor market. To illustrate the properties and quantitative implications of our model, we next examine two hypothetical policy scenarios assumed to take place after 2000, the elimination of early-retirement payments and the shift to a fully-funded pension scheme. We finally discuss the sensitivity of our results, especially with respect to international capital flows and annuity market imperfections.

\subsection{Base Scenario}

The base scenario incorporates the following exogenous shocks, described in the previous section: (i) decreasing mortality rates; (ii) fertility and migration shocks; (iii) a decreasing replacement rate $\rho_{t}^{i}$ after 2005, as a consequence of the 1993 and 2003 pension reforms. We simulate the model under the assumption that the year 1900 was a steady state. After 2100, all exogenous variables keep the same value and the economy progressively converges to a new, final steady state. The period of interest is the transition taking place during the 21st century (2000-2100). Values simulated for that sub-period are unlikely to be affected by the initial conditions (1900 values). 


\section{Main Results}

Figure 4 shows the change in some key variables in the base scenario (solid line). Disregard temporarily the dotted line. Population aging implies increased savings and capital accumulation (not shown in the figure). Because of diminishing returns, the interest rate decreases. Capital accumulation also leads to a substantial increase in average labor productivity (and wages). All this stimulates firms' profitability and the number of job openings. As a result, the aggregate employment rate increases. This higher employment rate also comes from the supply side through an increase in the participation rate of elderly workers (55-64). In an unchanged institutional environment, that is at given replacement rate, the higher participation rate of elderly workers (less early retirement) is due mainly to the increased probability of having a job (see Equation (12)), which we can interpret as a lower "discouragement" effect. Moreover, through the Euler equation, lower interest rates smooth the optimal consumption plan, which reinforces the labour supply of the elderly. Globally, between 2000 and 2100, the aggregate employment rate raises by about 6.4 percentage points. Figure 5 shows that the increase is much stronger for the oldest - working - generations. Moreover, we see that most of the increase is between 2000 and 2050 .

\section{[FIGURE 4 ABOUT HERE] [FIGURE 5 ABOUT HERE]}

The estimated cost of public pensions (including early-retirement benefits, and measured in $\%$ of GDP) follows quite closely the projected values for France given in EC (2009) for the period 2000-2060 and calculated under the assumption of an (approximately) 5 percentage

points (exogenous) increase in the aggregate employment rate. Thanks to the pension reforms decided in 1993-2003, the increase in public pension costs over the period 2000-2060 is no more than 1-1.5 percentage point (instead of 7 percentage points in a simulation without pension reform). We find however that, after 2070, the continuing aging of the population may lead to additional and substantial increases in the cost of public pensions.

\section{The Contribution of Fertility and Migration Shocks}

The cost of a given public pensions scheme in percent of GDP depends both on the expected increases in longevity and the size of the migration and fertility shocks. To separate these two effects, we simulated the model again with all fertility and migration variables set at their 2100 values. The results are summarized in Figure 6, which indicates by how much the cost of public pensions is changed by current and past fertility and migration shocks. During the first two decades, the effect is strongly negative. This is the continuation of the baby boom effect, which maintains the dependency ratio at low levels. After 2025, the effect becomes positive: baby-boomers retire, and the dependency ratio remains above normal for about five periods. 
After 2060, the effect of fertility and migration shocks becomes negligible, ie, the increase in the cost of public pensions after 2060 (see Figure 4) is solely driven by longevity effects.

[FIGURE 6 ABOUT HERE]

\subsection{Competitive vs Frictional Labor Markets}

Increased longevity changes the savings behavior of households and pushes the equilibrium interest rate downwards. Firms use more capital, which pushes labor productivity and labor demand upwards. The final impact on employment depends on the working of the labor market. In models with search frictions, labor demand changes may affect the equilibrium (un-)employment rate. To evaluate the quantitative importance of such adjustments along the extensive margin, we simulate the equilibrium with a frictionless labor market (Definition 2). The participation decision of elderly workers remains endogenous and determined in exactly the same fashion as before (see Equation (12) for workers aged 60-64), where the employment probability for participating workers is now equal to one $\left(\pi_{7, t+7}=1\right)$.

The comparison between the two economies is summarized in Figure 4. Values for the perfectly competitive economy are represented by a dotted line. In the competitive setup, employment rate changes can only arise from changes in the participation rate of elderly workers. Because there is no unemployment risk and the market wage is higher, there is little early-retirement in the competitive economy, although the generosity of the early-retirement scheme is the same as in the frictional labor market economy. Moreover, through the Euler equation, the lower interest rate in the competitive economy smoothes the increase in the optimal consumption plan, which implies relatively more labor supply at older ages.

Despite increased labor productivity and wages, the participation rate of elderly workers thus barely changes and has a negligible impact on the aggregate employment rate. The comparison with the frictional labor market economy is striking. In the frictional market, the increased labor demand leads to higher employment probabilities for all age groups. A higher employment probability has a significant impact on the participation of elderly workers. Overall, the employment rate increases significantly, and stimulates further capital accumulation and investment. Altogether, the aggregate employment rate increases by more than $6 \%$.

These differences explain why the two economies react differently to the pension reforms and the ensuing decrease in compensation rates. The cost of public pensions is initially smaller in the competitive economy (because there is less early-retirement). In the next 30 years, it increases by 2.7 percentage points and becomes larger than in the frictional economy (where the increase is 1.3 percentage points). This difference reflects the different impact of pension reforms on employment rates, and the failure of the competitive model to account for adjustments along 
the extensive margin. ${ }^{12}$

\subsection{Policy Scenarios}

We focus on two policy scenarios and compare their implications in the frictional and the competitive economies. The first scenario is a complete elimination of all early-retirement payments after 2000. The second is a shift to a fully-funded system, announced in 2005 and taking place in 2015. These two scenarios are admittedly extreme ones. They facilitate the comparisons between the two economies (frictional and competitive) and the interpretation of the mechanisms at work.

\section{Early-retirement reform}

\section{[FIGURE 7 ABOUT HERE]}

The consequences of the elimination of all early-retirement benefits are illustrated in Figure 7. This labor market policy change stimulates the participation of elderly workers, both in the frictional and in the competitive economy. All effects are qualitatively similar, but of a totally different magnitude, and much stronger in the frictional economy. In the competitive economy, because there is no unemployment and the equilibrium wage is higher, the initial participation rate is already high, and increases by 10 percentage points (from 85 to $95 \%$ at the time of the shock), compared to 25 percentage points (from 68 to 93\%) in the frictional economy. The induced impact effects on employment, capital productivity (the interest rate), wages and consumption (both decline at impact) are thus much more pronounced in the frictional economy. There is also (at impact) an increase in the unemployment rate of younger workers. Eventually, the unemployment rate returns to its initial value, but employment, wages and output increase more in the frictional economy. The cost of public pensions (in \% of GDP) decreases in the long run by 1.5 percentage points in the frictional economy (1 percentage point in the competitive economy). Short run effects are larger, because the activity rates of older workers also react in the longer run to changes in the unemployment rate and other variables engineered by capital accumulation and the falling interest rate.

Moreover, focusing on the frictional economy and comparing figures 4 and 7 , we observe that our early retirement reform almost completely offsets the public pension cost of the demographic shocks. We can relate this result to Haan and Prowse (2011). Using a different approach

\footnotetext{
${ }^{12}$ The comparison between the competitive and the frictional economies does not change much if we keep the activity rates of older workers fixed at their 2000 values. Employment rates then change only as a result of unemployment rate changes. In that scenario, the increase in pension costs between 2000 and 2035 is 1.11 percentage points larger in the competitive economy than in the frictional economy.
} 
(estimated life-cycle model on German micro-data), they show that the fiscal consequences of the anticipated increase in life expectancy can be offset by an increase of 4.3 years in the full pensionable age.

\section{Shift from a PAYG to a FF Pension Scheme}

Figure 8 illustrates the effects of announcing in 2005 that a shift to a purely fully-funded system will take place in 2015. We first consider the frictional economy. At impact, aggregate consumption falls, and savings and capital accumulation rise, which leads (with a one-period lag) to a lower interest rate. The accumulation of capital and its positive effect on labor productivity stimulates labor demand and job creation (the unemployment rate starts falling) as well as wage growth. The activity rate of elderly workers increases, by 12 percentage points at impact (when consumption has fallen) and 5 percentage points in the long run (when consumption has increased). The equilibrium unemployment rate is about 2.5 percentage points lower in the long run, and implies a substantially larger output (and consumption) level (not shown in the figure).

\section{[FIGURE 8 ABOUT HERE]}

In the competitive economy, the unemployment rate cannot vary; the participation rate of elderly workers increases by 3 percentage points. Aggregate employment barely changes. Capital accumulation leads to a larger output level, but this effect is not reinforced by job creation, as in the frictional economy.

\section{Sensitivity Analysis}

The objective of this section is to check to what extent our results might depend on specific assumptions. We repeated the previous simulation experiments for different values of a few key parameters: the subjective rate of time preference $(\theta=0$ instead of 0.01$)$, bargaining power $(\eta=0.70$ instead of 0.50$)$, concavity of leisure utility $(\phi=0.90$ or more, instead of 0.80$)$. Such changes did not alter our main conclusions and are not reproduced here. ${ }^{13}$ Instead we focus on the role of international capital flows and their interactions with labor market imperfections, as well as on the consequences of an imperfect annuity market.

\footnotetext{
${ }^{13}$ As discussed above, assuming linear preferences in leisure $(\phi=0)$ would imply an infinitely large Frisch elasticity and unrealistically large swings in participation rates.
} 


\subsection{International Capital Flows}

We here contrast the closed economy scenario with the small open economy one. In the latter, the interest rate is exogenous. Most actual economies are in between these two extremes.

\section{[FIGURE 9 ABOUT HERE]}

Figure 9 shows the development of the key variables already considered in the base scenario (see Figure 4) and compares them to the values obtained with the small open economy model. In both the closed and the small open economy, population aging implies increased savings and asset accumulation. In the small open economy, agents can borrow or lend freely from the rest of the world, at given interest rate, assumed to remain constant. In the closed economy, agents can only save by accumulating domestic capital; because of diminishing returns, the interest rate decreases. This difference in interest rates explains all the other differences. With constant returns to savings in the small open economy, per capita consumption remains almost constant during the demographic transition, while it substantially decreases in the closed economy. In the closed economy, domestic capital accumulation leads to a substantial increase in average labor productivity (hence in gross wages), and also an increase in aggregate employment. This higher employment level comes from both a decrease in the unemployment rate of young and mature workers (25-54) and from an increase in the participation rate of elderly workers (5564). These effects are related to capital accumulation and lower interest rates, which increase profitability and the number of job openings. These changes imply a higher optimal average retirement age (less early-retirement), in an unchanged institutional environment. These effects are non-existent in the small open economy with fixed interest rates. This contrast has large implications for the cost of public pensions. In the small open economy, population aging implies a 2 percentage point increase in the cost of public pensions between 2000 and 2060, compared to $0.5 \%$ in the closed economy. It is worth stressing that pension costs (in \% of GDP) evolve in similar ways in the small open economy with frictions and in the closed economy with perfect competition. This is because in both cases the employment level does not vary much and does not amplify the effects of policy changes.

Both Börsch-Supan et al. (2006) and Attanasio et al. (2007) have already stressed the role of international capital flows in determining how an economy will react to population aging. We obtain a similar conclusion and emphasize that in economies with a frictional labor market, changes in the equilibrium unemployment rate provide an additional mechanism by which international capital flows may affect the adjustment process and the future cost of public pensions (as a \% of GDP). With frictional labor markets, even the fiscal variables are affected by capital flows. 


\subsection{Imperfect annuity market}

So far, our model does not allow for uninsurable idiosyncratic risks. For instance, there exists a perfect insurance against individual lifetime uncertainty, as if there were a perfect annuity market. In practice, perfect annuities may not exist, forcing individuals to leave involuntary bequests and to consume less during their retirement period (Feldstein, 1990). In this section, we analyze the quantitative role of idiosyncratic uncertainty through an imperfect annuity market. ${ }^{14}$ To do so, we assume that if an individual dies at the end of a period, her financial wealth is not fully redistributed among surviving agents from the same generation but - partially - goes to the government. ${ }^{15}$ The budget constraint (11) becomes:

$$
\begin{aligned}
{\left[\left(1-\tau_{t+a}^{w}\right) w_{a, t+a} \cdot n_{a, t+a}\right.} & \left.+b_{a, t+a}^{u} \cdot u_{a, t+a}+b_{a, t+a}^{e} \cdot e_{a, t+a}\right] \cdot z_{a, t+a}+b_{a, t+a}^{i} \cdot\left(1-z_{a, t+a}\right) \\
& +\left(\frac{\beta_{a-1, t+a-1}}{\beta_{a, t+a}}\right)^{\varpi} R_{t+a} s_{a-1, t+a-1}=\left(1+\tau_{t+a}^{c}\right) c_{a, t+a}+s_{a, t+a}
\end{aligned}
$$

where $\varpi \in[0,1] . \varpi=1$ implies a perfect insurance against lifetime uncertainty as in the benchmark model whereas a lower $\varpi$ reduces the redistribution within a generation. This gives the Euler equation:

$$
\frac{u_{c_{a, t+a}}^{\prime}}{1+\tau_{t+a}^{c}}=\frac{1}{1+\theta}\left(\frac{\beta_{a+1, t+a+1}}{\beta_{a, t+a}}\right)^{1-\varpi} R_{t+a+1} \frac{u_{c_{a+1, t+a+1}}^{\prime}}{1+\tau_{t+a+1}^{c}} .
$$

It is worth noting that imperfect annuity market also modifies the government budget equation (23). Since the government partially receives unintended savings, the level of the consumption tax rate required to balance the budget can be reduced (from $20.1 \%$ in 2000 when $\varpi=1$ to $18.0 \%$ when $\varpi=0.8$ ). Figure 10 shows that introducing imperfect annuities reduces the income of the older generations, which decreases their savings and - especially - their consumption. Imperfect annuities therefore give a more realistic picture of the consumption distribution. Moreover, figure 11 shows that when a perfect insurance against longevity risks does not exist anymore, the younger generations (until 50) slightly increase their saving rate whereas the older generations reduce it. This setup therefore introduces precautionary saving motives.

\section{[FIGURE 10 ABOUT HERE] [FIGURE 11 ABOUT HERE]}

Although imperfect annuities reduce the level of activity, they do not affect significantly our main results. For instance, appendix B shows that the base scenario described in section 4.1

\footnotetext{
${ }^{14}$ Most papers with idiosyncratic uncertainty focus on the political support for social security reform. For instance, Conesa and Krueger (1998) and Nishiyama and Smetters (2007) show that the status quo bias in favor of an unfunded social security system is stronger in economies with uninsurable idiosyncratic risks. DíazGiménez and Díaz-Saavedra (2009) study the welfare implications of delaying the statutory retirement age.

${ }^{15}$ Alternatively, we could assume she leaves - unintended - bequests to a younger generation.
} 
and 4.2 remains almost unaffected by the introduction of imperfect annuities, both in the frictional or in the perfectly competitive setups. Our conclusions about the effects of policy changes as described in section 4.3 remain also mainly unchanged.

The fact that precautionary savings do not fundamentally change the effects of aggregate shocks is consistent with Krusell et al. (2010). They build a search and matching model with uninsurable idiosyncratic shocks. ${ }^{16}$ They show that incomplete markets do not quantitatively change the effects of aggregate shocks on labor market variables. However, the conclusions regarding the welfare analysis may substantially differ when incompleteness is taken into account.

\section{Conclusions}

We have introduced labor market frictions and early-retirement decisions into an otherwise standard OLG setup with population aging. In this setup, we show that population aging reduces the equilibrium unemployment rate, through its effect on capital accumulation, the interest rate and job openings. We have also shown that these effects can be substantially reinforced by endogenous participation rate changes (lower early-retirement rates).

Introducing frictions also changes the quantitative effects of policy changes (for instance lower retirement benefits), again via the effect of these policies on savings, the interest rate and equilibrium unemployment.

By contrasting the results obtained in the case of a small open economy with those of a closed economy, we have illustrated the importance of capital flows. When the interest rate is exogenously determined on world financial markets, population aging and pension reforms have similar effects on employment rates and the fiscal variables (public pension costs), although the implications for per capita consumption and the saving rate may be quite different.

In a two-country model, the interest rate would again be endogenous, and the new transmission mechanisms introduced by labor market frictions would work in much the same way as in the closed economy model, at least qualitatively. Future research should focus on interest rate determination and the impact of asymmetric labor market institutions in a multi-country setup.

\footnotetext{
${ }^{16}$ In our life-cycle setup, we introduce idiosyncratic risks through the lack of perfect annuities. Instead, Krusell et al. (2010) have infinitely-lived agents and introduce uninsurable earnings shocks.
} 


\section{Appendix A: The Household Optimization Problem}

With initial and final financial wealth equal to zero (no bequests), the household's intertemporal budget constraint can be written as: ${ }^{17}$

$$
\begin{array}{r}
\sum_{a=0}^{15} R_{t, t+a}^{-1} \beta_{a, t+a}\left\{\left[\left(1-\tau_{t+a}^{w}\right) w_{a, t+a} n_{a, t+a}+b_{a, t+a}^{u} u_{a, t+a}+b_{a, t+a}^{e} e_{a, t+a}\right.\right. \\
\left.\left.+b_{a, t+a}^{i} i_{a, t+a}\right] \cdot z_{a, t+a}-\left(1+\tau_{t+a}^{c}\right) c_{a, t+a}\right\}=0 .
\end{array}
$$

The discount factor $R_{t, t+a}$ is defined by $R_{t, t}=1$ and $R_{t, t+j}=\prod_{j=1}^{a} R_{t+j}$ for $j \geq 1$.

The values of $c_{a, t+a}, \lambda_{6, t+6}$ and $\lambda_{7, t+7}$ maximizing the household objective function (10) subject

to (5) and (9) and the intertemporal budget constraint (30) can thus be obtained from the maximization of the Lagrangean function

$$
\begin{array}{r}
\frac{W_{t}^{H}}{Z_{0, t}}=\max _{c_{a, t+a}, \lambda_{6, t+6}, \lambda_{7, t+7}} \sum_{a=0}^{15} \beta_{a, t+a}\left\{\beta^{a}\left(u\left(c_{a, t+a}\right)-d^{n} n_{a, t+a} \cdot z_{a, t+a}+d_{a}^{e} \frac{\left(e_{a, t+a}\right)^{1-\phi}}{1-\phi} z_{a, t+a}\right)\right. \\
+\mu_{t} R_{t, t+a}^{-1}\left(\left[b_{a, t+a}^{u}+\left(\left(1-\tau_{t+a}^{w}\right) w_{a, t+a}-b_{a, t+a}^{u}\right) n_{a, t+a}\right.\right. \\
\left.\left.\left.+\left(b_{a, t+a}^{e}-b_{a, t+a}^{u}\right) e_{a, t+a}\right] \cdot z_{a, t+a}-\left(1+\tau_{t+a}^{c}\right) c_{a, t+a}\right)\right\},
\end{array}
$$

where $\mu_{t}$ is the Lagrange multiplier associated with the intertemporal budget constraint. The optimal values of $c_{a, t+a}, \lambda_{6, t+6}$ and $\lambda_{7, t+7}$ must satisfy the first-order optimality conditions:

$$
\begin{aligned}
& \beta^{a} \frac{u_{c_{a, t+a}}^{\prime}}{1+\tau_{t+a}^{c}}=\mu_{t} R_{t, t+a}^{-1} \\
& {\left[d^{n} \frac{\partial n_{6, t+6}}{\partial \lambda_{6, t+6}}-d_{6}^{e}\left(e_{6, t+6}\right)^{-\phi} \frac{\partial e_{6, t+6}}{\partial \lambda_{6, t+6}}\right]+\beta \frac{\beta_{7, t+7}}{\beta_{6, t+6}}\left[d^{n} \frac{\partial n_{7, t+7}}{\partial \lambda_{6, t+6}}-d_{7}^{e}\left(e_{7, t+7}\right)^{-\phi} \frac{\partial e_{7, t+7}}{\partial \lambda_{6, t+6}}\right]} \\
& =\frac{u_{c_{6, t+6}^{\prime}}^{\prime}}{1+\tau_{t+6}^{c}}\left[\left(\left(1-\tau_{t+6}^{w}\right) w_{6, t+6}-b_{6, t+6}^{u}\right) \frac{\partial n_{6, t+6}}{\partial \lambda_{6, t+6}}+\left(b_{6, t+6}^{e}-b_{6, t+6}^{u}\right) \frac{\partial e_{6, t+6}}{\partial \lambda_{6, t+6}}\right] \\
& +\beta \frac{\beta_{7, t+7}}{\beta_{6, t+6}} \frac{u_{c_{7, t+7}}^{\prime}}{1+\tau_{t+7}^{c}}\left[\left(\left(1-\tau_{t+7}^{w}\right) w_{7, t+7}-b_{7, t+7}^{u}\right) \frac{\partial n_{7, t+7}}{\partial \lambda_{6, t+6}}+\left(b_{7, t+7}^{e}-b_{7, t+7}^{u}\right) \frac{\partial e_{7, t+7}}{\partial \lambda_{6, t+6}}\right] ; \\
& {\left[d^{n} \frac{\partial n_{7, t+7}}{\partial \lambda_{7, t+7}}-d_{7}^{e}\left(e_{7, t+7}\right)^{-\phi} \frac{\partial e_{7, t+7}}{\partial \lambda_{7, t+7}}\right]} \\
& =\frac{u_{c_{7, t+7}^{\prime}}^{\prime}}{1+\tau_{t+7}^{c}}\left[\left(\left(1-\tau_{t+7}^{w}\right) w_{7, t+7}-b_{7, t+7}^{u}\right) \frac{\partial n_{7, t+7}}{\partial \lambda_{7, t+7}}+\left(b_{7, t+7}^{e}-b_{7, t+7}^{u}\right) \frac{\partial e_{7, t+7}}{\partial \lambda_{7, t+7}}\right] .
\end{aligned}
$$

\footnotetext{
${ }^{17}$ It is clear from Equation (30) that consumption taxes have the same effect as income taxes.
} 
In these expressions,

$$
\begin{aligned}
& \frac{\partial e_{6, t+6}}{\partial \lambda_{6, t+6}}=1 ; \quad \frac{\partial e_{7, t+7}}{\partial \lambda_{6, t+6}}=\left(1-\lambda_{7, t+7}\right) ; \quad \frac{\partial e_{7, t+7}}{\partial \lambda_{7, t+7}}=\left(1-\lambda_{6, t+6}\right) ; \\
& \frac{\partial n_{6, t+6}}{\partial \lambda_{6, t+6}}=-\frac{n_{t+6}}{1-\lambda_{t+6}} ; \quad \frac{\partial n_{7, t+7}}{\partial \lambda_{6, t+6}}=-\frac{n_{t+7}}{1-\lambda_{t+6}} ; \quad \frac{\partial n_{7, t+7}}{\partial \lambda_{7, t+7}}=-\frac{n_{t+7}}{1-\lambda_{t+7}} .
\end{aligned}
$$

The first optimality condition (31) is the usual Euler condition. It implies that

$$
\frac{u_{c_{a, t+a}}^{\prime}}{1+\tau_{t+a}^{c}}=\beta R_{t+a+1} \frac{u_{c_{a+1, t+a+1}}^{\prime}}{1+\tau_{t+a+1}^{c}} .
$$

The other two optimality conditions are specific to this model and determine the activity rate of older workers. After substitution and rearrangement, and with the assumption that $u\left(c_{a, t+a}\right)$ is logarithmic, these optimality conditions can be recast as follows:

$$
\begin{aligned}
& {\left[\frac{b_{6, t+6}^{e}-b_{6, t+6}^{u}}{\left(1+\tau_{t+6}^{c}\right) c_{6, t+6}}+d_{6}^{e}\left(e_{6, t+6}\right)^{-\phi}\right]\left(1-e_{6, t+6}\right)} \\
& +\beta \frac{\beta_{7, t+7}}{\beta_{6, t+6}}\left[\frac{b_{7, t+7}^{e}-b_{7, t+7}^{u}}{\left(1+\tau_{t+7}^{c}\right) c_{7, t+7}}+d_{7}^{e}\left(e_{7, t+7}\right)^{-\phi}\right]\left(1-e_{7, t+7}\right) \\
& =\left[\frac{\left(1-\tau_{t+6}^{w}\right) w_{6, t+6}-b_{6, t+6}^{u}}{\left(1+\tau_{t+6}^{c}\right) c_{6, t+6}}-d^{n}\right] n_{6, t+6} \\
& +\beta \frac{\beta_{7, t+7}}{\beta_{6, t+6}}\left[\frac{\left(1-\tau_{t+7}^{w}\right) w_{7, t+7}-b_{7, t+7}^{u}}{\left(1+\tau_{t+7}^{c}\right) c_{7, t+7}}-d^{n}\right] n_{7, t+7}
\end{aligned}
$$

and

$$
\left[\frac{b_{7, t+7}^{e}-b_{7, t+7}^{u}}{\left(1+\tau_{t+7}^{c}\right) c_{7, t+7}}+d_{7}^{e}\left(e_{7, t+7}\right)^{-\phi}\right]\left(1-e_{7, t+7}\right)=\left[\frac{\left(1-\tau_{t+7}^{w}\right) w_{7, t+7}-b_{7, t+7}^{u}}{\left(1+\tau_{t+7}^{c}\right) c_{7, t+7}}-d^{n}\right] n_{7, t+7} .
$$

The economic interpretation of these optimality conditions becomes easier if we note that the unconditional probability of having a job is given by

$$
\pi_{a, t+a}=\frac{n_{a, t+a}}{n_{a, t+a}+u_{a, t+a}}=\frac{n_{a, t+a}}{1-e_{a, t+a}}
$$

so that the last optimality condition can be written as

$$
\frac{b_{7, t+7}^{e}}{\left(1+\tau_{t+7}^{c}\right) c_{7, t+7}}+d_{7}^{e}\left(e_{7, t+7}\right)^{-\phi}=\pi_{7, t+7}\left[\frac{\left(1-\tau_{t+7}^{w}\right) w_{7, t+7}}{\left(1+\tau_{t+7}^{c}\right) c_{7, t+7}}-d^{n}\right]+\left(1-\pi_{7, t+7}\right)\left[\frac{b_{7, t+7}^{u}}{\left(1+\tau_{t+7}^{c}\right) c_{7, t+7}}\right],
$$

and similarly for the other optimality condition.

\section{Appendix B: Base scenario with imperfect annuities}

We here reproduce the base scenario of sections 4.1 and 4.2 (effects of demography and past pension reforms in frictional (solid line) and perfectly competitive (dotted line) economies) but 
with imperfect annuities. We see the results are very to those displayed in Figure 4. We obtain the same similarities when simulating the other scenarios.

[FIGURE 12 ABOUT HERE] 


\section{References}

Attanasio, O., Kitao, S. , Violante, G.L., 2007. Global demographic trends and social security reform. Journal of Monetary Economics 54(1), 144-198.

Aubert, P., Crépon, B., 2003. La productivité des salariés âgés : une tentative d'estimation. Économie et Statistique 368(1), 95-119.

Auerbach, A., Kotlikoff, L., 1987. Dynamic Fiscal Policy. Cambridge University Press, Cambridge.

Azariadis, C., Bullard, J., Ohanian, L., 2004. Trend-reverting fluctuations in the life-cycle model. Journal of Economic Theory 119, 334-356.

Bassanini, A., Marianna, P., 2009. Looking inside the perpetual-motion machine: Job and worker flows in the OECD countries. OECD Social, Employment and Migration Working Papers no. 95, OECD, Paris.

Börsch-Supan, A., Ludwig, A., Winter, J., 2002. Aging and International Capital Flows, in: Auerbach, A.J., Herrmann, H. (Eds.), Ageing, Financial Markets and Monetary Policy, Springer Verlag, Heidelberg, pp. 55-83.

Börsch-Supan, A., Ludwig, A., Winter, J., 2006. Aging, pension reform, and capital flows: a multi-country simulation model. Economica 73(292), 625-658.

Börsch-Supan, A., Ludwig, A., 2010. Old Europe is aging: reforms and reform backlashes, in: Shoven, J. (Ed.), Demography and the Economy, University of Chicago Press, Chicago, pp. 169-204.

Boucekkine, R., de la Croix, D., Licandro, O., 2002. Vintage human capital, demographic trends, and endogenous growth. Journal of Economic Theory 104, 340-375.

Bozio, 2008. How elastic is The response of retirement-age labor supply? Evidence from the 1993 French reform, in: de Menil, G., Pestieau, P., Fenger, R. (Eds), Pension Strategies in Europe and the United-States, MIT Press, Cambridge, pp. 37-85.

Carnegie-Rochester Conference, 2007. Economic Consequences of Demographic Change in a Global Economy. Journal of Monetary Economics 54(1), 1-228.

Chéron A., Hairault, J.O., Langot, F., 2008. Life-cycle equilibrium unemployment. IZA Discussion Paper 3396.

Chéron A., Hairault, J.O., Langot, F., 2011. Age-dependent employment protection. Economic Journal 121(557), 1477-1504.

Conesa, J., Krueger, D., 1999. Social Security Reform with Heterogeneous Agents. Review of Economic Dynamics 2, 757-795. 
Den Haan, W.J., Kaltenbrunner, G., 2009. Anticipated growth and business cycles in matching models. Journal of Monetary Economics 56(3), 309-327.

de la Croix, D., Docquier, F., Liégeois, P., 2007. Income growth in the 21st century: forecasts with an overlapping generations model. International Journal of Forecasting 23, 621-635.

de la Croix, D., Mahieu, G., Rillaers, A., 2004. How should the allocation of resources adjust to the baby bust? Journal of Public Economic Theory 6(4), 607-636.

de Walque, G., Pierrard, O., Sneessens, H., Wouters, R., 2009. Sequential Bargaining in a NeoKeynesian Model with Frictional Unemployment and Staggered Wage Negotiations. Annals of Economics and Statistics 95/96, 221-250.

Díaz-Giménez, J., Díaz-Saavedra, J., 2009. Delaying retirement in Spain. Review of Economic Dynamics 12, 147-167.

Duval, R., 2003. The retirement effects of old-age pension and early-retirement schemes in OECD countries. OECD Economics Department, Working Papers, No. 370, OECD Publishing.

EC, 2009. Pension schemes and pension projections in the EU-27 Member States - 2008-2060.

Occasional Papers 56, Volume I, October (French report prepared by Thibault Guyon, Falilou Fall and Franck Arnaud).

Farm, A., 2004. A theory of vacancies. Working Paper 1/2005, Swedish Institute for Social Research (SOFI), Stockholm University.

Feldstein, M., 1990. Imperfect annuity markets, unintended bequests, and the optimal age structure of social security benefits. Journal of Public Economics 41, 31-43.

Fondeur, Y., Zanda, J.-L., 2009. Les emplois vacants. Connaissance de l'emploi no 64, Centre d'Etudes de l'Emploi.

Frick, J., Grabka, M., Groh-Samberg, O., 2011. The impact of home production on economic inequality in Germany. Empirical Economics, forthcoming.

Giannelli, G., Mangiavacchi, L., Piccoli, L., 2012. GDP and the value of family caretaking: how much does Europe care? Applied Economics 44(16), 2111-2131.

Gruber, J., Wise, D.A., 1999. Social Security Programs and Retirement around the World. University of Chicago Press, Chicago.

Gruber, J., Wise, D.A., 2004. Social Security Programs and Retirement around the World: Microestimation. University of Chicago Press, Chicago.

Gruber, J., Wise, D.A., 2005. Social security programs and retirement around the world: Fiscal implications. NBER Working Paper 11290, Cambridge, MA. 
Haan, P., Prowse, V., 2011. Longevity, Life-cycle Behavior and Pension Reform. Working Paper 556, University of Oxford.

Hairault, J.O, Langot, F., 2008. Inequality and social security reforms. Journal of Economic Dynamics and Control 32, 386-410.

Hairault, J.O., Langot, F., Sopraseuth, T., 2010. Distance to retirement and older workers' employment: the case for delaying the retirement age. Journal of the European Economic Association 8 (5), 1034-1076.

Heijdra, B.J., Romp, W.E., 2009. Retirement, pensions and aging. Journal of Public Economics $93,586-604$.

Hu, S. C., 1979. Social security, the supply of labor and capital accumulation. American Economic Review 69(3), 274-283.

Johnson, R. W., Neumark, D., 1996. Wage Declines among Older Men. The Review of Economics and Statistics 78(4), 740-48.

Kotlikoff, L. J., Gokhale, J., 1992. Estimating a firm's age-productivity profile using the present value of workers' earnings. The Quarterly Journal of Economics 107(4), 1215-42.

Krueger, D., Ludwig, A., 2007. On the consequences of demographic change for rates of returns to capital, and the distribution of wealth and welfare. Journal of Monetary Economics 54, 4987.

Krusell, P., Mukoyama, T., Sahin, A., 2010. Labour-Market Matching with Precautionary Savings and Aggregate Fluctuations. Review of Economic Studies 77, 1477-1507.

Lucas, D., 2007. Comment on "Global demographic trends and social security reform" by Attanasio, O., Kitao, S., Violante, G., Journal of Monetary Economics 54, 199-204.

McCall, J., 1970. Economics of information and job search. Quarterly Journal of Economics 84, 113-126.

Michel, P., Pestieau, P. 1999. Social security and early-retirement in an overlapping generations growth model. CORE Discussion Paper 9951, published in French as: Retraite par répartition et âge de la retraite. Revue économique 51(2000), 15-30.

Mortensen, D.T., Pissarides, C., 1994. Job creation and job destruction in the theory of unemployment. Review of Economic Studies 61, 397-415.

Nishiyama, S., Smetters, K., 2007. Does social security privatization produce efficiency gains? The Quarterly Journal of Economics 1677-1719.

OECD, 2007. Pensions at a Glance. OECD publishing, Paris.

OECD, 2009. Employment Outlook. OECD publishing, Paris. 
Pissarides, C.A., 2000. Equilibrium Unemployment Theory, 2nd ed. MIT Press, Cambridge. Ravn, M.O. , 2008. The consumption-tightness puzzle, in: Reichlin, L., West, K. (Eds), NBER International Seminar on Macroeconomics, University of Chicago Press, Chicago , pp. 9-63. Ríos-Rull, J.V., 1996. Life-Cycle Economies and Aggregate Fluctuations. The Review of Economic Studies 63, 465-489.

Ríos-Rull, J.-V., 2001. Population changes and capital accumulation: the aging of the baby boom. Advances in Macroeconomics, The B.E. Journals in Macroeconomics 0 (1).

Robert-Bobée, I., 2006. Projections de population 2005-2050 pour la France métropolitaine - Méthodes et résultats. Document de travail F0603, INSEE, Division des Etudes Démographiques, Paris.

Rogerson, R., 1988. Indivisible labor, lotteries and equilibrium. Journal of Monetary Economics $21,3-16$.

Tripier, F., 2003. Can the labor market search model explain the fluctuations of allocations of time? Economic Modelling 21, 131-146.

Vallin, J., Meslé, F., 2001. Tables de mortalité françaises pour les XIXe et XXe siècles et projections pour le XXIe siècle. Données statistiques, no 4, INED, Paris. 


\begin{tabular}{lr|lr}
\hline Symbol & Value & Symbol & Value \\
\hline \multicolumn{4}{c}{ Production function } \\
$A$ & 20.000 & $\alpha$ \\
$\delta$ (quarterly) & 0.025 & 0.33
\end{tabular}

\section{Age-dependent productivity}

\begin{tabular}{ll|ll}
$h_{0}$ & 2.70 & $h_{1}$ & 3.30 \\
$h_{2}$ & 3.85 & $h_{3}$ & 4.45 \\
$h_{4}$ & 5.00 & $h_{5}$ & 5.80 \\
$h_{6}$ & 5.60 & $h_{7}$ & 5.50
\end{tabular}

\section{Preferences}

\begin{tabular}{ll|ll}
$\theta$ (quarterly) & 0.010 & $d^{n}$ & 0.250 \\
$d_{6}^{e}$ & 0.031 & $d_{7}^{e}$ & 0.049 \\
$\phi$ & 0.800 & &
\end{tabular}

\begin{tabular}{lr|lr}
\multicolumn{4}{c}{ Labor Market } \\
$\mu$ & 0.90 & $\nu$ & \\
$\chi$ (quarterly) & 0.02 & $\mathrm{a}$ & 0.50 \\
$\eta$ & 0.50 & & 43.50
\end{tabular}

\begin{tabular}{lr|ll}
\multicolumn{4}{c}{ Policy variables } \\
$\zeta$ & 0.35 & $\tau^{w}$ & 0.150 \\
$\bar{g}$ & 0.20 & $\rho^{u}$ & 0.400 \\
$\rho^{e}$ & 0.50 & $\rho_{t}^{i}($ year 2000) & 0.550 \\
$\rho_{t}^{i}($ year 2050) & 0.35 & $\rho_{t}^{i}($ year 2100) & 0.325 \\
\hline
\end{tabular}

Table 1: Parameter values 
Figure 1: Employment rates per age in 2010: EU15 data vs. model

Figure 2: Projected age-specific death rates (left), (adult) population growth and dependency ratio (right)

Figure 3: Eigenvalues of the model with (circles) and without (squares) frictions

Figure 4: The base scenario in frictional (solid line) and perfectly competitive (dotted line) economies

Figure 5: Employment rate across generations

Figure 6: Contributions of fertility and migration shocks to the cost of public pensions (changes in $\%$ of GDP)

Figure 7: The consequences of eliminating early-retirement benefits after 2000, in the frictional (solid line) and the competitive (dotted line) economy

Figure 8: The consequences of announcing in 2005 a shift to a fully-funded system in 2015, in the frictional (solid line) and the competitive (dotted line) economy

Figure 9: Comparing the closed (solid line) and the small open economy (dotted line) scenarios

Figure 10: Consumption and savings across generations in 2000: comparing the perfect annuity market $(\varpi=1$, solid line) and the imperfect annuity market ( $\varpi=0.8$, dotted line) 
Figure 11: Saving rate across generations in 2000: comparing the perfect annuity market $(\varpi=1$, solid line) and the imperfect annuity market $(\varpi=0.8$, dotted line)

Figure 12: Base scenario with imperfect annuities, with (solid line) and without (dotted line) labor market frictions 